\title{
From the Editor-in-Chief
}

\section{Home Care: We Want More}

In this issue we are publishing two research papers on home care. Readers will recall that we also recently profiled Shirlee Sharkey, Executive Director of Saint Elizabeth Health Care, and Judith Shamian, President and CEO of the Victorian Order of Nurses. ${ }^{1}$ It therefore seems appropriate to reflect here on home care from the perspective of this journal.

The two research studies in this issue are different in almost every respect, including focus, purpose, method and province involved. One is from Quebec and reports an innovative way of managing the complex end of home care by using hospital-based nursing staff. The other, from British Columbia, focuses on case managers as they absorb the changes they are required to make in their chronic care services by administrators who, in turn, must respond to budget constraints. One study is upbeat as it describes an innovation that has promise. The other reveals the distress experienced by front-line workers who must reduce services they know their clients need and deserve. In some ways, the two studies reveal the best and the worst of home care: enormous opportunities, and day-to-day struggles just to keep going.

We do not receive many research reports that involve home care. It is unclear whether this dearth reflects a health sector that receives little research attention, or whether the research that is done is not viewed as relevant for this journal. Neither reason provides comfort, since our mandate is to report on innovations, research and strategies for leadership development.

Home care is the sector touted, in every report on the future of healthcare in Canada, as fundamental to the future of the system, a sector that must grow in order to manage the increased complexity that the system will generate. Developments in technology will continue to push the frontiers of medical treatment and result in patients spending less rather than more time in hospital. Experience has shown that many of these patients will be in frail health after discharge and will require continued treatments and expert supervision and care. While this aspect of the healthcare system is developing, the population continues to age, and most older people will wish to remain in their own homes for as long as possible. Accommodating this demand requires a whole spectrum of services, ranging from homemaking and groundskeeping to assistance with personal care, 
and monitoring and managing a complex array of chronic illnesses. Given the present and envisioned future of home care, the sector should be a beehive of research activity, and we should have a research report or a report of an innovation in virtually every issue of this journal. The development of leaders is critical for this sector to respond to the enormous opportunities and challenges facing it.

Because home care is not covered by the Canada Health Act, different provinces use a variety of funding and delivery models. The Canadian Home Care Human Resources Study (2003) reports that between 8,600 and 9,700 registered nurses (depending on who is counting) are employed in home care; $29 \%$ of them work for private, for-profit agencies. This fact alone sets the sector apart from acute care, where virtually all hospitals are in the public sector. In Western Canada and Quebec, and to some extent in the East, home care nurses work for regional health authorities or their equivalents. In Ontario, private, not-for-profit (usually, Saint Elizabeth and VON) and for-profit agencies compete to secure contracts with the government organizations that manage and fund home care. This bidding process creates an unstable environment: if agencies do not win contracts, staff are laid off. Further, a high proportion of nurses in for-profit agencies are hired on a casual basis to keep employer costs down. They therefore receive no fringe benefits such as vacation, sick leave or pensions, and their salaries are lower than those of nurses working in other sectors (Canadian Home Care Human Resources Study 2003). These employment features are much less common in the other provinces.

In an Ontario-based study (Denton et al. 2002), home care is described as a sector that can take a heavy toll on the health of those who work in it, despite the fact that these registered and practical nurses, social workers, occupational and physical therapists have high self-esteem, a sense of mastery and loyalty to their employing agencies. The negative health effects are attributed to restructuring and organizational change in the sector. Outside of Ontario, home care, despite considerable financial constraint - which produces heavy caseloads and concern from nurses about the quality of care they are able to deliver - has not been subject to the same restructuring and destabilizing pressures.

This variation in organizational models - for-profit and not-for-profit, public and private employers, casual versus full-time employment - creates the opportunity to answer questions about their effectiveness and efficiency, for recipients of care and for the nurses who provide it. The Highlights report of the Home Care Human Resources Study (2001) notes that as demand outstrips the funding capacity of agencies, home care decision-makers must rationalize services, often in the absence of evidence about which services make the greatest difference, and to whom. Why is there no evidence? 
Home care nursing has a long and proud history in Canada. Nurse-led organizations such as VON Canada and Saint Elizabeth Health Care have been innovators in the field since the late 1800s and early 1900s, respectively. Those health authorities that have integrated services across sectors have created programs that are highly responsive to clients' needs - for example, the CHOICE program (Comprehensive Home Option for Integrated Care of the Elderly) in the Capital Health Region in Alberta. The future dictates that the home care sector must flourish if the entire health system is to be sustained. Home care needs great leadership to stimulate the development of innovations and research to put information into the hands of decision-makers. This journal will publish the research and reports of these innovations, and will showcase the leaders. We just want more!

\section{Notes}

${ }^{1}$ See "Shirlee Sharkey: Extraordinary Things Are Possible," Canadian Journal of Nursing Leadership 18(4): 28-28 (http://www.longwoods.com/product.php?productid=17829\&cat=\&page $=1$ ) and "Judith Shamian: Be True to Yourself and Your Values," Canadian Journal of Nursing Leadership 18(3): 19-22 (http://www.longwoods.com/product.php?productid=17613\&cat=395\&page=1).

\section{References}

Canadian Home Care Human Resources Study. Phase 1 Highlights. Setting the Stage: What Shapes the Home Care Labour Market? 2001. Retrieved February 21, 2006. <http://www.cacc-acssc.com/english/ pdf/homecareresources/highlights-final.pdf $>$.

Canadian Home Care Human Resources Study. Technical Report. 2003. Retrieved February 21, 2006. $<$ http://www.cacc-acssc.com/english/pdf/homecareresources/EngTechnic.pdf $>$.

Denton, M., I.U. Zeytinoglu and S. Davies. 2002. "Organizational Change and the Health and Wellbeing of Home Care Workers.” Retrieved February 21, 2006. <http://www.wsib.on.ca/wsib/wsibsite. nsf/public/researchresultsdenton>.

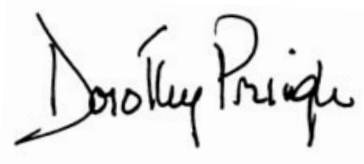

Dorothy Pringle, $\mathrm{PhD}$

Editor-in-Chief 